\title{
Library Expenditures: An Examination of Their Distribution
}

$\mathrm{I}^{\mathrm{r}}$ IS PROBABLY an understatement to say that library budgets have received a lot of attention. Investigations have been on both broad and narrow scales, by real and pseudo-statisticians, based on valid and invalid figures and premises. But interest continues and not without cause. In his desire for guides, for standards of operation in a field combining so peculiarly scholarship and business, romance, and cold, hard cash, the librarian continues to examine all facets of his activity for aid in developing a sound and justifiable modus operandi. With all the logic, clear and concentrated thought, theorizing, and so forth that have been applied to the problem in the past, few areas within the compass of the library's operations have been defined in terms of measurable standards, and when it comes to explaining with sound calculations the requirements of the library budget, we are truly fortunate that many controlling authorities simply accept our requests. And if the users be satisfied with the service, we have the strongest justification for our actions.

Among the factors which may be questioned in a budget is the internal breakdown, the percentage of the total budget allotted to the various major and minor subdivisions. "Am I allowing too much for salaries, or too little?" or "Why so much for salaries? What about books?" And the question immediately comes to mind: "Is there any typical distribu-

Dr. Harrer is chief acquisition librarian, Stanford University Libraries; he was formerly associate order librarian, University of Tennessee. tion?" It is often assumed by those dealing with the subject that the larger the library the greater the cost of administration. In the larger libraries, then, we would expect a larger percentage of the budget to be allotted to salaries and less to books, binding, and periodicals. If there is such a fluctuation, it might seem hardly worth while to look for a typical breakdown. But an examination of the figures, I believe, produces some interesting results.

I have taken as a basis for calculation the expenditures of the "Group I" libraries as published in the January, 1955, C\&RL, Vol. 17, No. 1, pp. 58-61. There are 107 libraries listed. Unfortunately, some have not supplied complete statistics and cannot, therefore, be used here. For purposes of determining the distribution of funds into the three principal pigeon holes, "Salaries," "Books, etc.," and "Other," all libraries have been included except Yale, which supplied only the first two items. For investigation of the subbreakdowns, eight other libraries must be discarded. It was also felt justifiable to rule out one other library because of an extremely abnormal distribution of funds, showing almost as much spent on "Other" as on "Salaries."

First, take the ninety-eight complete sets of figures, add the columns, and determine the typical percentage distribution of funds. We arrive at the figures shown in Table I.

Then, an analysis of the three large subdivisions of the expenditures of libraries grouped by size gives the figures in Table II. 
TABLE I

Typical Percentage Distribution of Funds for 98 Group I Libraries

\begin{tabular}{crr|rrr|rr}
\hline \hline $\begin{array}{c}\text { Staff } \\
\text { Salaries }\end{array}$ & $\begin{array}{c}\text { Student } \\
\text { Service }\end{array}$ & Total & Books & Binding & Total & Other & $\begin{array}{r}\text { Grand } \\
\text { Total }\end{array}$ \\
\hline$* *$ & $* *$ & 63.4 & $* *$ & $* *$ & 31.9 & 4.7 & 100.0 \\
85.9 & 14.1 & 100.0 & 84.2 & 15.8 & 100.0 & $* *$ & $* *$ \\
\hline
\end{tabular}

TABLE II

\begin{tabular}{ccccc}
\hline \hline Bookstocks & $\begin{array}{l}\text { No. of } \\
\text { Libs. }\end{array}$ & Salaries & $\begin{array}{c}\text { Books w } \\
\text { Binding }\end{array}$ & Other \\
\hline Up to 350M & 42 & 64.21 & 31.58 & 4.19 \\
350M- 600M & 24 & 63.33 & 31.82 & 4.84 \\
600M-900M & 19 & 61.87 & 32.96 & 5.15 \\
$900 \mathrm{M}-1400 \mathrm{M}$ & 10 & 64.43 & 30.01 & 5.55 \\
1400M-3000M & 8 & 67.59 & 27.81 & 4.59 \\
\hline
\end{tabular}

Several observations may be made. First, there is a fluctuation, but not a steady increase. Administration, as represented here by salaries, apparently costs more in the smaller libraries of this group as well as in the larger, although not as much more. Secondly, more may be spent on "Books and Binding" in libraries of 600,000 to 900,000 bookstock, where there is the lowest cost of administration. There is also an increase in "Other Operating Expenses" for this group, the reason for which is open to speculation.

An analysis of the "Salaries" figure shows that the two components, "Staff Salaries" and "Student Service," split the total as follows:

\begin{tabular}{rcc}
\hline \hline Bookstock & $\begin{array}{c}\text { Staff } \\
\text { Salaries }\end{array}$ & $\begin{array}{c}\text { Student } \\
\text { Service }\end{array}$ \\
\hline $350 \mathrm{M}$ & 84.62 & 15.37 \\
$600 \mathrm{M}-600 \mathrm{M}$ & 86.55 & 13.44 \\
$900 \mathrm{M}-1400 \mathrm{M}$ & 86.63 & 13.36 \\
$1400 \mathrm{M}-3000 \mathrm{M}$ & 84.01 & 15.98 \\
& 84.41 & 15.58 \\
\hline
\end{tabular}

The figures show a tendency toward a smaller proportion's being spent on student service in the middle range. An at- tempt to correlate this with a similar trend in the proportion of student hours to staff hours worked in this group was inconclusive because of scanty figures. The cause of this trend, then, is yet to be determined.

The "Books and Binding" group breaks down as follows:

\begin{tabular}{rcc}
\hline \hline Bookstock & $\begin{array}{l}\text { Books and } \\
\text { Periodicals }\end{array}$ & Binding \\
\hline 350M & 84.78 & 15.21 \\
$600 \mathrm{M}-600 \mathrm{M}$ & 86.59 & 13.40 \\
$900 \mathrm{M}-1400 \mathrm{M}$ & 86.68 & 13.31 \\
$1400 \mathrm{M}-3000 \mathrm{M}$ & 83.67 & $16-32$ \\
& 82.42 & 17.57 \\
\hline
\end{tabular}

Here again we see a general trend from the smaller libraries to the middle group with its low proportion spent on binding and then back in the case of the largest libraries. (An interesting coincidence is the similarity of these figures to those in the breakdown of "Salaries.") Whether this figure would correlate with a similar trend in the number of periodicals acquired as compared to books in these libraries is, as above, uncertain because of incomplete figures on which to base such a calculation. 
Now, all the above figures are of interest for several reasons. In the first place, definite progressions in the distribution of funds are apparent in the various size groups. And, in all but one instance, the medium-size libraries show one extreme, while the smaller and/or larger libraries show the other. The group with between 600,000 and 900,000 bookstock is able to spend the most on materials, and, within that figure, more proportionately on books. In the "Other Operating Expenditures," however, the high is not reached in this group, but in the next larger.

A further question immediately presents itself-a question of real complications and ramifications. What feature or features can be determined to be the primary causes of this fluctuation in distribution? This is, of course, a matter of correlating the fluctuation of some other measurable feature of the library situation with the changes in the distribution of funds within the library budget.

Is it, for instance, the size of the book budget or the size of the book collection which causes libraries to have similar expenditure distribution? Then a further thought occurs: "Is it possible that the relation of these two features to each other would have an effect on the internal distribution of funds?" For instance, if a library had a large collection and a small book budget, would this cause the librarian to allocate more of his funds to staff salaries and less to building the collection? We could easily use the amount (in dollars and cents) spent per book in the collection as a measure of this relationship, but a further question also presents itself: "How large is the public which is served?"

The larger the student body the greater amount, very probably, that would have to be spent on staff, all other factors being equal. It is obvious at this point that we are getting into an almost insoluble problem. To mention briefly other factors which would no doubt have an effect on the internal distribution of funds, we could bring up the composition of the student body, i.e., percentage of graduate students and number of faculty; the number of departmental libraries (as suggested above); the types of courses offered-whether primarily in sciences, agriculture, engineering, the humanities; the availability of the books-whether to a large extent on open stacks or closed, whether primarily on reserve for reading courses or not; and finally, the quality of service offered by the library, a product of all the above features. For this last, I can see no way to produce a statistical figure. But it may, in the final analysis, be the most important.

These figures, however, demonstrate one other very interesting fact: that there is actually little variation in the various size groups. The largest variation is in the figures in the "Salaries" column between the 600,000 to 900,000 and the $1,400,000$ to $3,000,000$ groups, a difference of 5.72 per cent. And the progression from one figure to the other may be expected to be regular.

This sort of breakdown can be used for general checking purposes against individual budgets. If any figure in a given budget is found to be more than, say, eight to ten per cent from the general average, there may be a reason for it; but an investigation would at least bring such deviations to light and allow for questions. If it is discovered, as in the case of one library on the list, that only 20 per cent of the total budget was spent on "Books and Binding" (as compared to a norm of 31.88 per cent for the size group) and, of that, 90 per cent is spent on books, leaving binding with only ten per cent (as compared to the normal split of 85-15 per cent), it is possible that investigation will show a justification for redistribution of funds. 